GU J Sci, Part C, 7(4): 776-787(2019)

Gazi Üniversitesi
Fen Bilimleri Dergisi
PART C: TASARIM VE TEKNOLOJI
http://dergipark.gov.tr/gujsc

\title{
Production of $\mathrm{Al}-\mathrm{Si}_{3} \mathrm{~N}_{4}$ Powder Metal Composite Material and Investigation of Wear Behavior
}

\author{
Halil ARIK \\ Gazi University Faculty of Technology, Department of Metallurgical and Materials Engineering,06500, Yenimahalle/ANKARA
}

\section{Graphical/Tabular Abstract}

\section{Article Info:}

Research article

Received: 17/09/2019

Revision: 01/10/2019

Accepted: 06/10/2019

\section{Highlights}

- Distribution of $\mathrm{Si}_{3} \mathrm{~N}_{4}$ in matrix structure.

- Improving of wear performance of composite

\section{Keywords}

Powder Metallurgy, Composite Material, $\mathrm{Al}_{-} \mathrm{Si}_{3} \mathrm{~N}_{4}$, Wear Behaviors.
In this study, it is aimed to determine the effect of $\mathrm{Si}_{3} \mathrm{~N}_{4}$ ratio on wear behavior of aluminum matrix composite material produced by powder metallurgy method. Mixed aluminum powders containing $5 \%, 10 \%$ and $15 \%$ by weight $\alpha-\mathrm{Si}_{3} \mathrm{~N}_{4}$ were pressed in the die under $500 \mathrm{MPa}$ pressure and $10 \mathrm{~mm}$ diameter and $15 \mathrm{~mm}$ length block samples were produced. Then pressed samples were sintered in an atmosphere controlled tube furnace for 2 hours at $650^{\circ} \mathrm{C}$. After the characterization study such as density and hardness measurements, dry sliding wear test all of the composite materials were performed by using pin-on-disk method. The tests were carried out on the TIRIBOMETER T10 / 20 abrasion tester according to ASTM G99-05. Dry sliding wear tests of composite were carried out under the different load (5-10-15 N) and at $1.41 \mathrm{~m} / \mathrm{s}$ sliding speed for $2000 \mathrm{~m}$ wear distance. Wear test results showed that composite materials containing silicon nitride at different ratio have better wear resistance according to matrix powder metal parts produced under the same conditions.

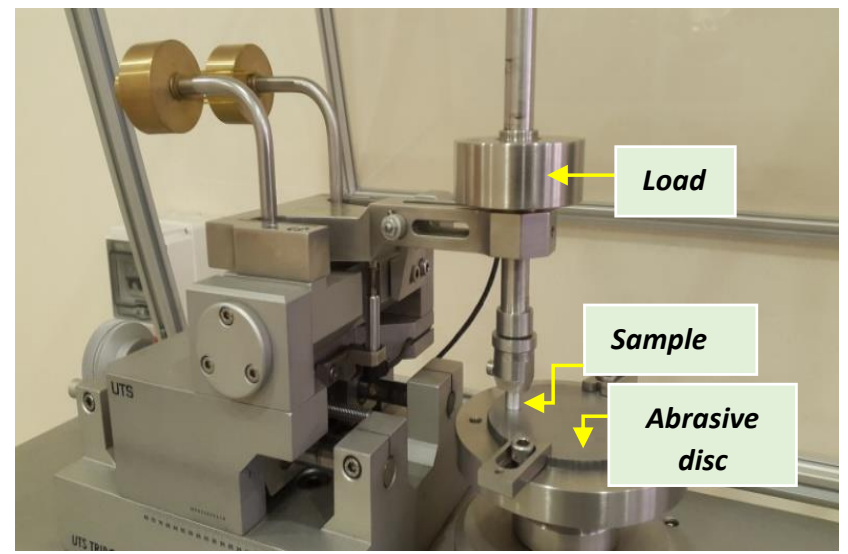

Figure A. Abrasion tester machine

Purpose: The main purpose of this study, investigation of the effects of $\alpha-\mathrm{Si}_{3} \mathrm{~N}_{4}$ as a reinforcing element on the wear performance of aluminum matrix composite materials.

Theory and Methods: In this study, for $\mathrm{Al}-\alpha-\mathrm{Si}_{3} \mathrm{~N}_{4}$ composite materials, powder metallurgy as a production method and dry sliding pin-on disc method as wearing method were used

Results: The homogeneous distribution of $\mathrm{Al}-\alpha-\mathrm{Si}_{3} \mathrm{~N}_{4}$ powders in each other has been accomplished successfully by mixing process in the adritor. The hardness values of all samples increased after the sintering process. when silicon nitride ratio used in matrix structure increased hardness of composite materials increased also. According to the abrasion test results, while the applied load increased, amount of wear losses increased in all samples. Wear losses decreased while reinforcing ratio increased in composite.

Conclusion: It was observed that density, hardness and abrasion performance of composite samples produced by powder metallurgy method improved considerably according to matrix material. 
GU J Sci, Part C, 7( 4 ): 776-787 (2019)

Gazi Üniversitesi
Fen Bilimleri Dergisi
PART C: TASARIM VE TEKNOLOJI
http://dergipark.gov.tr/gujsc

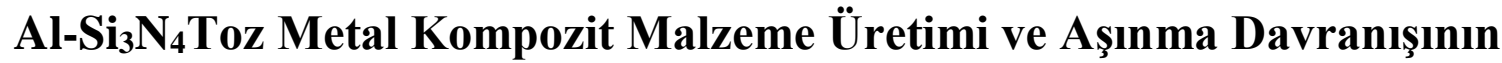 Araştırılması
}

\author{
Halil ARIK \\ Gazi Üniversitesi, Teknoloji Fakültesi, Metalurji ve Malzeme Mühendisliği Bölümü, 06500,Yenimahalle/ANKARA
}

\section{$\ddot{O} \mathbf{z}$}

\begin{tabular}{l} 
Makale Bilgisi \\
\hline Araştırma makalesi \\
Başvuru: $17 / 09 / 2019$ \\
Düzeltme: $01 / 10 / 2019$ \\
Kabul: 06/10/2019 \\
Anahtar Kelimeler \\
\hline Toz Metalurjisi, \\
Kompozit Malzeme, \\
Al-Si $i_{3} N_{4}$, \\
Aşınma Davranışı.
\end{tabular}

Keywords

Powder Metallurgy, Composite Material, $\mathrm{Al}_{-} \mathrm{Si}_{3} \mathrm{~N}_{4}$, Wear Behaviour.
Alüminyum ve alaşımları başta otomotiv ve havacılık sektörü olmak üzere pek çok alanda tercih edilen metal ve alaşım grubunu oluşturmaktadır. Alüminyum alaşımlarının üstün özellikleri yanında sertlik ve aşınma direnci gibi özelliklerinin bazı uygulamalarda beklentilerin uzağında kalması alüminyum matrisli kompozit malzeme üretimi çalışmalarını daha değerli ve gerekli kılmaktadır. Bu çalışmada toz metalürjisi metodu ile üretilen $\alpha-\mathrm{Si}_{3} \mathrm{~N}_{4}$ içeren alüminyum matrisli kompozit malzemelerde takviye elemanı oranının kompozitin aşınma davranışı üzerine etkilerinin belirlenmesi amaçlanmıştır. Ağırlıkça $\% 5, \% 10$ ve $\% 15$ oranlarında $\alpha$-Si3 $\mathrm{N}_{4}$ içeren karışım tozlar kalıp içerisinde $500 \mathrm{MPa}$ basınç altında preslenerek $10 \mathrm{~mm}$ çapta ve $15 \mathrm{~mm}$ boyda blok numuneler üretilmiştir. Daha sonra preslenen numuneler atmosfer kontrollü tüp firında 2 saat süreyle $650{ }^{\circ} \mathrm{C}$ sıcaklıkta sinterlenmiştir. Toz metal kompozit parçaların yoğunluk ve sertlik ölçümleri sonrası pin-on-disk metoduyla kuru kayma aşınma testleri yapılmıştır. Testler TIRIBOMETER T10/20 aşındırma test cihazında ASTM G99-05' göre yapılmıştır. Aşındırma testleri $1,41 \mathrm{~m} / \mathrm{s}$ kayma hızı ve $2000 \mathrm{~m}$ mesafede farklı yükler (5-10-15 N) altında tekrarlanmıştır. Alınan aşınma test sonuçları aynı şartlarda üretilen matris malzemeye göre değişik oranlarda $\alpha$ $\mathrm{Si}_{3} \mathrm{~N}_{4}$ takviyeli kompozitlerin daha iyi aşınma direncinde sahip olduğunu göstermektedir. En yüksek aşınma direnci ve sertlik değerleri ağırlıkça \% 15 silisyum nitrür içeren kompozit malzemede görülmüştür.

\section{Production of Al-Si3 $\mathrm{N}_{4}$ Powder Metal Composite Material and Investigation of Wear Behavior}

\begin{abstract}
Aluminum and its alloys as a structural materials are preferred in many fields, especially in the automotive and aerospace sectors. Conversly to many superior properties of aluminum and its alloys the fact that its properties such as hardness and wear resistance are far from the expectations in some applications makes the production of aluminum matrix composite materials more valuable and necessary. In this study, it is aimed to determine the effect of $\mathrm{Si}_{3} \mathrm{~N}_{4}$ ratio on wear behavior of aluminum matrix composite material produced by powder metallurgy method. Mixed aluminum powders containing $5 \%, 10 \%$ and $15 \%$ by weight $\alpha-\mathrm{Si}_{3} \mathrm{~N}_{4}$ were pressed in the die under $500 \mathrm{MPa}$ pressure and $10 \mathrm{~mm}$ diameter and $15 \mathrm{~mm}$ length block samples were produced. Then pressed samples were sintered in an atmosphere controlled tube furnace for 2 hours at 650 ${ }^{\circ} \mathrm{C}$. After the characterization study such as density and hardness measurements, dry sliding wear test all of the composite materials were performed by using pin-on-disk method. The tests were carried out on the TIRIBOMETER T10 / 20 abrasion tester according to ASTM G99-05. Dry sliding wear tests of composite were carried out under the different load (5-10-15 N) and at 1.41 $\mathrm{m} / \mathrm{s}$ sliding speed for $2000 \mathrm{~m}$ wear distance. Wear test results showed that composite materials containing silicon nitride at different ratio have better wear resistance according to matrix powder metal parts produced under the same conditions. The highest wear resistance and hardness values were seen at composite materials.
\end{abstract}

\section{GİRIŞ (INTRODUCTION)}

Alüminyum ve alaşımları hafif olmaları, ssı ve elektriği iyi iletmeleri, oksidasyon dirençlerinin ve özgül ağırlıklarına oranla yüksek mukavemete sahip olmalarından dolayı uzay ve havacılık başta olmak üzere 
pek çok sektörde yoğun şekilde tüketilmektedir. Buna karşılık yüksek sıcaklık ve aşındırıcı ortamlardaki performansının beklentilerin gerisinde kalması alüminyum matrisli ve seramik parçacık takviyeli kompozit malzeme üretimi üzerine yapılan çalışmalara hız vermiştir. Alüminyum matrisli seramik takviyeli kompozit malzeme üretimi genel olarak ergiyik veya katı hal yöntemi şeklinde gerçekleştirilmektedir [1-5]. Ergiyik yöntemle kompozit üretiminde ergiyik metal içerisine değişen oranlarda bir veya daha fazla tür seramik esaslı $\mathrm{SiC}, \mathrm{Al}_{4} \mathrm{C}_{3}, \mathrm{~B}_{4} \mathrm{C}, \mathrm{Al}_{2} \mathrm{O}_{3}, \mathrm{Si}_{3} \mathrm{~N}_{4}$ gibi karbür, oksit veya nitrür tipi katı parçacık şeklinde takviye elemanı ilavesi yapılarak kompozit üretimi gerçekleştirilmektedir. Katı hal yöntemi olarak ise yoğun şekilde toz metalürjisi metodu ile toz metal kompozit parça üretimi yapılmaktadır [6-11].

$\mathrm{Bu}$ yöntemle üretimde alüminyum-seramik karışım tozların kalıp içerisinde preslenmesi sonrası atmosfer kontrollü ortamlarda uygun sicaklık ve sürede sinterlenmesi veya presleme ve sinterlemenin aynı anda gerçekleştirildiği sıcak presleme şeklinde üretim yapılabilmektedir [12-14]. Katı hal yöntemine göre ergiyik yöntemle daha yoğun ve mukavim kompozit malzeme üretimi yapılabilirken seramik partiküllerin matris yapı içindeki dağılımında görülen düzensizlikler ve ergiyik matris yapı tarafından katı seramik partiküllerin ıslatılabilirliğinin yeterli olmadığı durumlarda ara yüzeydeki bağlanmanın zayıf kalması sıkça karşılaşılan problemlerdir. Ayrıca ergiyik yöntemle üretilen kompozit malzemelerden parça imalatında talaşlı imalat şeklindeki bitirme işçiliklerinde kesici takım aşınmaları ve gerekli parça yüzey kalitesini elde etmedeki güçlükler bu uygulamanın dezavantajlı yanları olarak sıralanabilir. Toz metalürjisi metodu ile üretimde seri üretim şeklinde kısa sürede çok sayıda parça üretimi, çoğu durumda üretimi hedeflenen parçanın nihai ölçülerinde ve yüzey kalitesinde veya buna çok yakın parça üretimi yapılabilmektedir. Böylece sert ve talaşlı imalatı zor seramik takviye elemanı içeren toz metal parçalar üzerinden talaşlı işleme ile yapılan sonlandırma işçilikleri en aza inebilmektedir. Üretilecek toz metal kompozit parçalarda yüksek yoğunluk ve mukavemet hedeflendiği durumlarda sıcak presleme şeklinde üretim tercih edilebilir. Ancak sıcak presleme ile parça üretimi hızlı ve seri imalatı ortadan kaldıran bir handikapa sahiptir [15-18].

$\mathrm{Bu}$ çalışmada değişen molar oranlarda $\alpha-\mathrm{Si}_{3} \mathrm{~N}_{4}$ içeren alüminyum matrisli kompozit üretimi klasik toz metalürjisi üretim aşamaları uygulanarak gerçekleştirilmiştir. Literatür taramasında alüminyum matrisli partikül takviyeli kompozit üretiminde yoğun olarak $\mathrm{SiC}, \mathrm{B}_{4} \mathrm{C}$ veya $\mathrm{Al}_{2} \mathrm{O}_{3}$ gibi karbür yada oksit takviyeli kompozit üretimi üzerine çalışmalar yapıldığı görülmektedir [19-22]. Son yıllarda yapılan çalışmalarda ise birden fazla takviye elemanı içeren hibrit türü kompozit üretimi üzerine yapılan çalışmalarda bir artış görülmekte. Özellikle alüminyum matrisli seramik takviyeli üretilen kompozitlerin tiribolojik özelliklerini iyileştirmek için değişen oranlarda grafit kullanıldığı görülmekte [23-26]. Alüminyum matrisli kompozit üretiminde $\alpha-\mathrm{Si}_{3} \mathrm{~N}_{4}$ takviyeli çalışmaların çok az olması $\mathrm{SiC}$ veya $\mathrm{Al}_{2} \mathrm{O}_{3}$ ' göre maliyetinin yüksek olmasından en önemli sebeptir [27-28]. Pek çok parçanın kullanın yerinde değişik etkenler tesiri altında aşınmasının parçanın kullanım ömrünü azalttığı, çalışma performansını düşürdüğü veya üretimde ürün ve hizmet kalitesini olumsuz etkilediği, bazı hallerde ciddi iş kazalarına sebep olduğu bilinmekte. Aşınmaya maruz kalan bu tür parçaların aşınmaya karşı dayancını artırmaya yönelik çalışmalar her geçen gün daha da önemli hale gelmektedir. Bu sebeple, metal esaslı parçaların aşınmaya karşı aşınma kayıplarının etkili bir şekilde azaltılması ve kontrolü her zaman istenen bir durumdur [29-30]. Bu çalışmada literatürdeki benzer çalışmalardan farlı olarak ultra düşük partikül boyut aralığında $(0,1-0,3 \mu \mathrm{m}) \alpha-\mathrm{Si}_{3} \mathrm{~N}_{4}$ takviye elemanı kullanılırken her iki tozun birbiri içerisindeki karışımını daha homojen kılmak ve matrisle seramik partiküllerin bağlanmasını güçlendirmek için karıştırma işlemi çelik bilye içeren yüksek enerjili atritörde gerçekleştirilmiştir.

\section{DENEYSEL ÇALIŞMALAR (EXPERIMENTAL STUDY)}

$\mathrm{Bu}$ çalışmada üretilmek istenen $\mathrm{Al}$ metal matrisli ve $\alpha-\mathrm{Si}_{3} \mathrm{~N}_{4}$ parçacık takviyeli toz metal kompozit malzeme için matris malzemesi olarak ECKART Dorn firmasından temin edilen \% 97,9 saflıkta ve toz tane boyutu $200 \mu \mathrm{m}$ altı ECKA AS 91/S serisi atomize alüminyum tozu kullanılmıştır. Takviye elemanı olarak T\&N TECHNOLOGY LTD firmasından temin edilen $0,1-0,3 \mu \mathrm{m}$ parçacık boyut aralığında $\alpha-\mathrm{Si}_{3} \mathrm{~N}_{4}$ tozu kullanılmıştır. Ağırlıkça \% 5-10 ve 15 oranında $\alpha-\mathrm{Si}_{3} \mathrm{~N}_{4}$ içeren karışım tozların hassas tartımlar sonrası karıştırma işlemi şekil 1'de verilen yüksek enerjili atritörde yapılmıştır. Mekanik olarak tozların karıştırılması süresince alüminyum tozun birbirine kaynak olmasını ve ortamdaki bilye, karıştırıcı kollar ve 
atritör tankı yüzeyine sıvanmasını önlemek amacıyla ortama ağırlıkça \%1,5 oranında yağlayıcı olarak çinko stereat (ZnSt) ilave edilmiştir (Tablo 1).

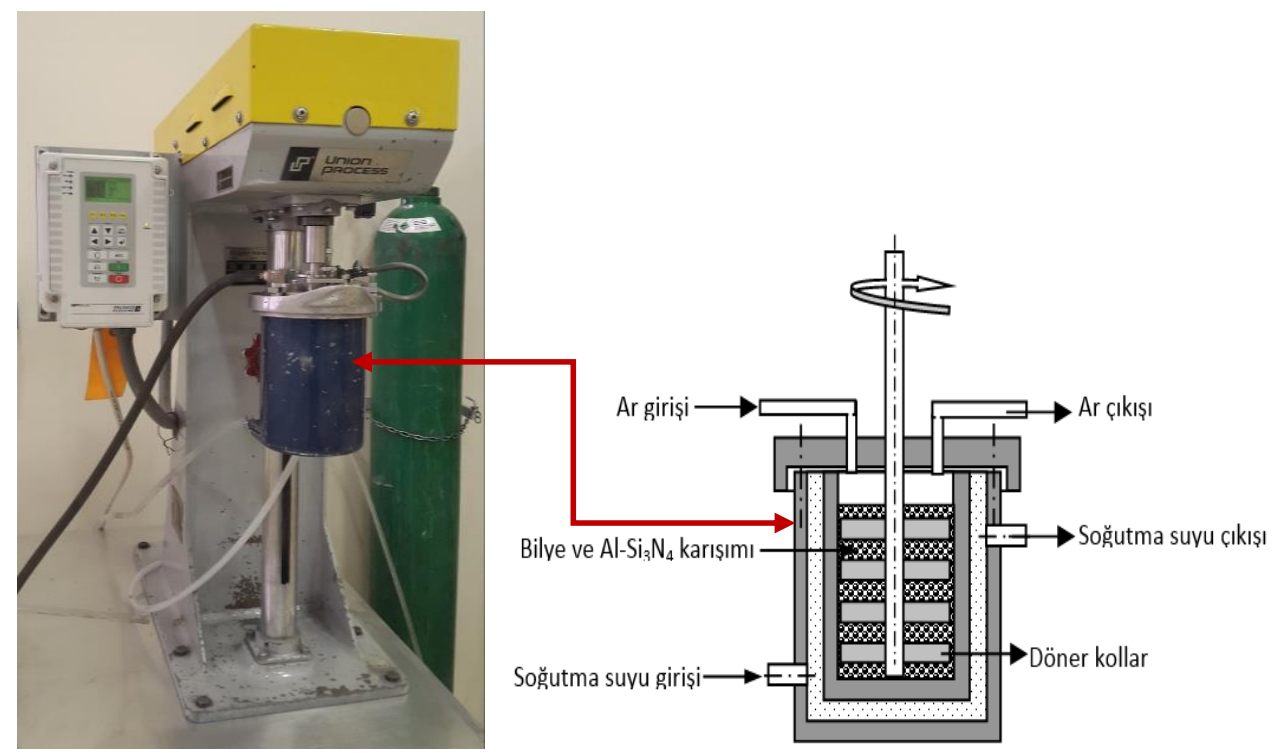

Şekil 1. Yüksek enerjili atritör

Tablo 1. Mekanik karıştırma parametreleri.

\begin{tabular}{|c|c|c|c|c|c|c|}
\hline Numune & $\begin{array}{c}\text { Karışım } \\
\text { malzeme }\end{array}$ & $\begin{array}{c}\text { ZnSt. (\% ağırlık } \\
\text { olarak) }\end{array}$ & $\begin{array}{c}\text { Ağırlık olarak çelik } \\
\text { bilye/ Toz oranı }\end{array}$ & $\begin{array}{c}\text { Karıştırma } \\
\text { süresi (saat) }\end{array}$ & $\begin{array}{c}\text { Karıştırma } \\
\text { atmosferi }\end{array}$ & $\begin{array}{c}\text { Karıştırma } \\
\text { (dev/dak.) }\end{array}$ \\
\hline 1 & $\mathrm{Al}+\% 5 \alpha-\mathrm{Si}_{3} \mathrm{~N}_{4}$ & 1,5 & $10: 1$ & 2 & $\mathrm{Ar}$ & 450 \\
\hline 2 & $\mathrm{Al}+\% 10 \alpha-\mathrm{Si}_{3} \mathrm{~N}_{4}$ & 1,5 & $10: 1$ & 2 & $\mathrm{Ar}$ & 450 \\
\hline 3 & $\mathrm{Al}+\% 15 \alpha-\mathrm{Si}_{3} \mathrm{~N}_{4}$ & 1,5 & $10: 1$ & 2 & $\mathrm{Ar}$ & 450 \\
\hline
\end{tabular}

Karıştırma sırasında karıştırma ortamına oksitlenmeyi önlemek için koruyucu argon gazı beslenirken uygulamaya bağlı açığa çıkacak ısınmayı önlemek için de sürekli olarak suyla soğutma sağlanmıştır. Karıştırma sonrası elde edilen tozlardan $500 \mathrm{MPa}$ basınç altında tek yönlü eksenel kalıpta $10 \mathrm{~mm}$ çapta ve $15 \mathrm{~mm}$ boyda silindirik blok numuneler preslendi (Şekil 2). Presleme sonrası ham yoğunluk ölçümleri yapılan numuneler atmosfer kontrollü tüp firında sinterlendi. Numuneler grafit kayık içerisinde tüp firın merkezine yerleştirildikten sonra firın sinterleme sıcaklığına $\left(650^{\circ} \mathrm{C}\right)$ kadar $5^{\circ} \mathrm{C} /$ dak. hızla yükseltildi ve bu sıcaklıkta 2 saat bekletildi. Sinterleme süresi bitiminde firın kontrollü olarak oda sicaklığına soğutuldu.

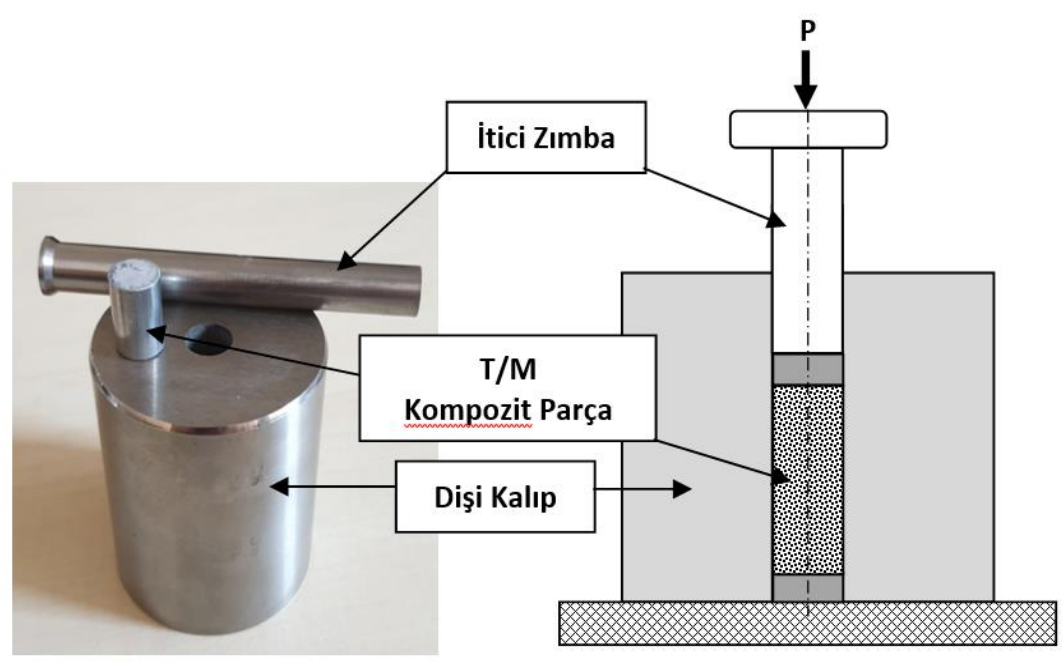

Şekil 2. Toz metal kompozit numunelerin preslenmesi 
Sinterlenen numunelerin yoğunluk ölçümleri $0,1 \mathrm{mg}$ hassasiyette tartım yapabilen hassas terazide yoğunluk kiti kullanılarak arşiment prensibine göre yapıldı. Numunelerin brinell cinsinden sertlik ölçümleri 31,25 kgf yük altında ve $2,5 \mathrm{~mm}$ çapta tungsten karbür standart bilye kullanılarak gerçekleştirildi. Her numune üzerinden 5 farklı ölçüm yapıldı ve ortalaması toz metal kompozit numunelerin sertlik değeri olarak alındı. Metalografik inceleme için sıcak bakalite alma işlemi sonrası numune yüzeyleri sirayla 320-1200 $\mu \mathrm{m}$ aralığında SiC zımpara kağıdında zımparalama ve devamında 6-3 ve $1 \mu \mathrm{m}$ elmas solüsyon kullanılarak parlatılmıştır. Numune yüzeyinden optik ve SEM-EDX görüntüleri alınarak kompozit numuneler sinterleşme ve faz dağılımı bakımından incelenmiştir.

\subsection{Aşınma Testi (Wear Test)}

Üretilen toz metal parçaların karakterizasyon çalışmaları sonrası farklı oranlarda takviye elemanı içeren kompozit numunelerin Pin-on-disk metodu ile kuru kayma aşınma testleri yapıldı. Testler Şekil 3 'te verilen UST TIRIBOMETER T10/20 cihazı kullanılarak yapıldı. Aşındırma test değişkenleri tablo 2' verilmiştir. Aşındırma testi öncesi her numunenin yüzeyleri hassas olarak temizlenmiş ve daha sonra $0,1 \mathrm{mg}$ ölçüm hassasiyetinde hassas terazide ağırlık tartımları yapılmıştır. Aşındırma testi öncesi ve sonrası ölçülen ağırlık değerlerinden hareketle toz metal numunelerdeki aşınmaya bağlı ağırlık kayıpları belirlenmiştir.

Tablo 2. Malzeme ve pin-on-disk aşındirma test değişkenleri

\begin{tabular}{|c|c|c|c|c|c|c|}
\hline Numune & Karışım malzeme & $\begin{array}{c}\text { Kayma } \\
\text { hızı (m/s) }\end{array}$ & $\begin{array}{c}\text { Kayma } \\
\text { mesafesi (m) }\end{array}$ & $\begin{array}{c}\text { Uygulanan } \\
\text { yük (N) }\end{array}$ & $\begin{array}{l}\text { Aşındırıcı } \\
\text { çelik disk }\end{array}$ & $\begin{array}{l}\text { Aşındırma } \\
\text { standardı }\end{array}$ \\
\hline 1 & $\mathrm{Al}$ & \multirow{4}{*}{1,41} & \multirow{4}{*}{2000} & \multirow{4}{*}{$5-10-15$} & \multirow{4}{*}{$\begin{array}{c}\text { Hardox-500 } \\
\text { (52 HRc) }\end{array}$} & \multirow{4}{*}{$\begin{array}{c}\text { ASTM } \\
\text { G99-05 }\end{array}$} \\
\hline 2 & $\mathrm{Al}+\% 5 \alpha-\mathrm{Si}_{3} \mathrm{~N}_{4}$ & & & & & \\
\hline 3 & $\mathrm{Al}+\% 10 \alpha-\mathrm{Si}_{3} \mathrm{~N}_{4}$ & & & & & \\
\hline 4 & $\mathrm{Al}+\% 15 \alpha-\mathrm{Si}_{3} \mathrm{~N}_{4}$ & & & & & \\
\hline
\end{tabular}

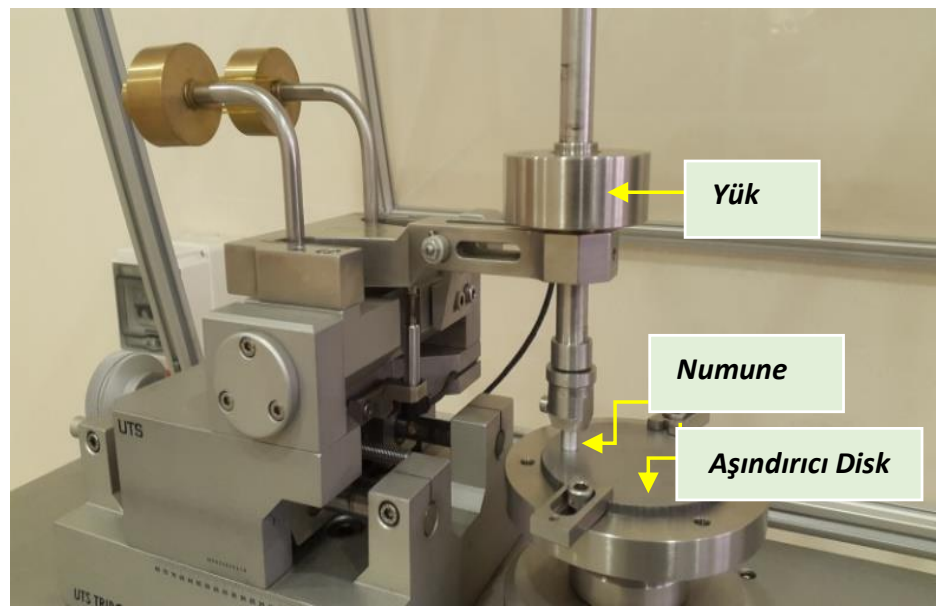

Şekil 3. Pin-on-disk aşındırma test cihazı

\section{SONUÇLAR VE TARTIŞMA (RESULTS AND DISCUSION)}

Atritörde karıştırma sonrası $\% 5 \alpha-\mathrm{Si}_{3} \mathrm{~N}_{4}$ içeren karışım tozun şeklinde ve ortalama toz tane boyutunda önemli bir değişme görülmezken, \% $10 \alpha-\mathrm{Si}_{3} \mathrm{~N}_{4}$ içeren karışım tozda toz tane boyutu ortalama değeri 42,23 $\mu \mathrm{m}$ ' ye kadar düşmüştür. Burada takviye elemanı kompozit tozun sertliğini artırıp, deforme olarak sekil değişimini önemli ölçüde sınırlandırmakta ve kompozit toz partiküllerinde parçalanarak boyutta küçülme daha etkili şekilde ortaya çıkmaktadır. $\% 15 \alpha-\mathrm{Si}_{3} \mathrm{~N}_{4}$ içeren karışım tozda ise matris yapıyı oluşturan alüminyum toz partiküllerinin kısmen birbirine kaynaklanarak aglomera olduğu görülmekte. Bu durum karışım tozun ortalama toz tane boyutunun $\% 10 \alpha-\mathrm{Si}_{3} \mathrm{~N}_{4}$ içeren karışım toza göre bir miktar artmasına neden olmuştur. $\mathrm{Bu}$ durum özellikle ortama yağlayıcı katılmadığı veya yağlayıcının yetersiz kaldığı durumlarda ortaya çıkan bir problemdir [31]. 
Bütün numunelerde sinterleme öncesi ham yoğunluk değerlerine göre sinterleme sonrası yoğunluk değerlerinin arttığı görülmekte. $\% 15 \alpha-\mathrm{Si}_{3} \mathrm{~N}_{4}$ içeren numunede takviye elemanı oranındaki artı̧̧ kompozitte sinterleşmeyi kısmen engelleyip \% $10 \alpha-\mathrm{Si}_{3} \mathrm{~N}_{4}$ içeren numuneye göre bir miktar yoğunluğun düşmesine sebep olmuştur. Metal matrisli kompozit malzemelerde seramik partikül takviye oranı artarken toz metal blok malzemelerde sinterleşme ve yoğunluk artışı azalmaktadır. Sertlik ölçüm sonuçları matris yapıya göre bütün kompozit numunelerde daha yüksek sertlik değerleri elde edildiğini gösterirken aynı zamanda takviye oranı artışının kompozit malzemelerin sertlik değerlerini de aynı şekilde artırdığını göstermektedir (Tablo $3)$.

Tablo 3. Numunelerin yoğunluk, sertlik ve ortalama toz parçacık boyutundaki değişim

\begin{tabular}{|l|c|c|c|c|}
\hline \multicolumn{1}{|c|}{ Karışım toz } & $\begin{array}{c}\text { Ortalama toz tane } \\
\text { boyutu }(\mu \mathrm{m})\end{array}$ & $\begin{array}{c}\text { Ham yoğunluk } \\
(\%)\end{array}$ & $\begin{array}{c}\text { Sinterleme sonras1 } \\
\text { yoğunluk }(\%)\end{array}$ & Sertlik (HBw) \\
\hline Saf $\mathrm{Al}$ & 104,86 & 97,6 & 97,8 & 46,1 \\
\hline $\mathrm{Al}+5 \% \alpha-\mathrm{Si}_{3} \mathrm{~N}_{4}$ & 97,87 & 91,5 & 94,5 & 65,9 \\
\hline $\mathrm{Al}+10 \% \alpha-\mathrm{Si}_{3} \mathrm{~N}_{4}$ & 42,23 & 94 & 97,1 & 70,0 \\
\hline $\mathrm{Al}+15 \% \alpha-\mathrm{Si}_{3} \mathrm{~N}_{4}$ & 61,02 & 92 & 94,6 & 76,1 \\
\hline
\end{tabular}

Aşıımma testleri sonrası numune kompozisyonuna ve uygulanan yüke bağlı ağırlık kayıplarındaki değişim Şekil 4'te görülmekte. $5 \mathrm{~N}$ yük altında gerçekleştirilen aşındırma testleri sonrası sırayla matris malzemede $11,3 \mathrm{mg}, \% 5 \alpha-\mathrm{Si}_{3} \mathrm{~N}_{4}$ içeren kompozitte 5,8 mg, \%10 $\alpha-\mathrm{Si}_{3} \mathrm{~N}_{4}$ içeren kompozitte 3,4 mg ve $\% 15 \alpha-\mathrm{Si}_{3} \mathrm{~N}_{4}$ içeren numunede 1,9 mg ağırlık kaybı olduğu görülmekte. Elde edilen sonuçlar matris malzemeye göre $\alpha$ $\mathrm{Si}_{3} \mathrm{~N}_{4}$ içeren kompozit malzemelerin aşınma kayıplarında ciddi bir azalma olduğunu göstermektedir. Aşındırmaya bağlı ağırlık kayıplarında matris malzemeye göre sırayla $\% 5 \alpha-\mathrm{Si}_{3} \mathrm{~N}_{4}$ içeren kompozitte \% 48,67, \% $10 \alpha-\mathrm{Si}_{3} \mathrm{~N}_{4}$ içeren kompozitte \% 69,91 ve \% $15 \alpha-\mathrm{Si}_{3} \mathrm{~N}_{4}$ içeren kompozitte \% 83,18; nispetinde azalma görülüştür (Şekil 4). Uygulanan $5 \mathrm{~N}$ yük altında ortaya çıkan ağırlık kayıplarına göre takviye elemanı ilavesinin matris malzemenin aşınma direncinde ciddi bir iyileşme sağladığı görülmekte. Takviye elemanı oranı artarken aşınma kayıplarının da hızla düştüğü görülmektedir.

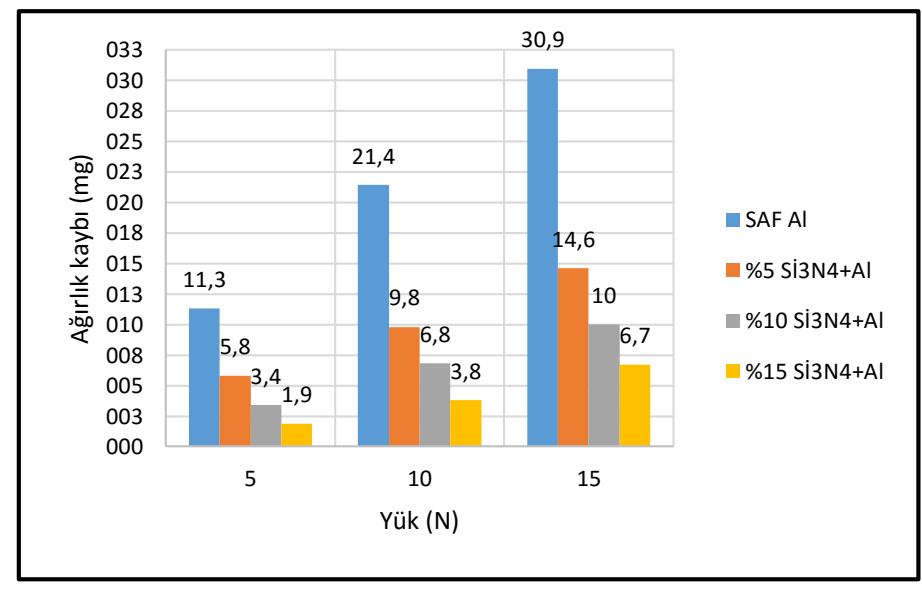

Şekil 4. Yüke ve malzeme kompozisyonuna bağlı aşınma kaybı değerlerindeki değişim

Test sonuçlarına göre uygulanan yük artarken bütün numunelerde aşınma değerleri artmıştır. $5 \mathrm{~N}$ yük altında matris malzemede ağılık kaybı 11,3 mg iken aynı şartlarda $10 \mathrm{~N}$ yük altında \% 89,38 artarak, 21,4 mg'a, 15 N yük altında \% 173,4 artarak 30,9 mg değerine yükselmiştir. Bu sonuçlar literatür taramasında görülen benzer çalışmalarla da uyumludur. Aşınmaya etkiyen diğer parametreler değişmediği sürece uygulanan yük artarken aşınma değerleri artmaktadır [32-34].

Kompozit numunelerde de aynı şekilde yük artışına bağlı aşınma değerleri artmıştır. Örneğin $\% 15 \alpha-\mathrm{Si}_{3} \mathrm{~N}_{4}$ içeren kompozitte $5 \mathrm{~N}$ yük altında $1,9 \mathrm{mg}$ ağırlık kaybı olurken, $10 \mathrm{~N}$ yük altında $\% 100$ artarak 3,8 mg, 15 $\mathrm{N}$ yük altında \% 252,6 artarak 6,7 mg ağırlık kaybı ortaya çıkmıştır. Elde edilen sonuçlar yük artışına bağlı olarak matris malzemeye göre kompozit malzemelerdeki ağırlık kaybı oranlarının bir miktar yüksek olduğu 
görülmekte. Bunun temel sebebi matris malzemeden üretilen numuneler aşındırılırken karşı aşındırıcı disk yüzeyinde ciddi bir bozulma oluşturmazken, kompozit numunelerde durum farklıdır. Kompozit numuneler kendileri aşınırken içerdiği seramik takviye elemanının tesiriyle karşı disk yüzeyini de çizerek ve yüzey pürüzlülüğünü bozarak çelik diskin aşındırma etkisini artırmaktadır. Numunelerin aynı iz üzerinde dairesel dönme hareketi yaparak aşındığını düşünürsek aşındırıcı yüzeydeki her tür bozulma test numunesinin aşınma değerlerini doğrudan etkilemektedir.

Burada görülen etki aşındırıcı disk yüzeyinin bozulmaya bağlı olarak test numunesini aşındırma etkisinin daha da artmış olacağı şeklindedir. Buna göre mevcut elde edilen aşınma değerlerinin disk yüzeyindeki bozulma ve artan aşındırma etkisinden dolayı olması gerekenden bir miktar daha fazla olduğunu söyleyebiliriz. Yani kompozit malzemeler mevcut disk üzerinde aşındırılırken disk yüzeyinde herhangi bir bozulma olmasaydı kompozit numunelerin matris malzemeye göre aşınma kaybı değerleri çok daha düşük olacaktı. Seramik parçacık takviyeli kompozit malzemelerin pin-on-disk metodu ile çelik disk üzerinde aşınma testlerinde pratik olarak bu olumsuzluğu ortadan kaldırmak kolay değildir. Bu çalışmada olduğu gibi takviye elemanı partikül boyutu ne kadar küçük olursa aşındırıcı karşı diskin aşındırılan numuneden etkilemesi o derece düşük olacaktır. Seramik partikül boyutu büyük olan kompozit malzemelerde seramik parçacıkların çizerek çelik diski aşındırma etkisi daha yüksek olacaktır. Aşındırılan numunelerin $\alpha-\mathrm{Si}_{3} \mathrm{~N}_{4}$ içeriğine ve uygulanan yüke bağlı olarak belirli mesafelerdeki (500-1000-1500-2000 m) sürtünme katsayıs1 değerleri incelendiğinde genel olarak matris malzemeye göre kompozit malzemedeki sürtünme katsayıs1 değerlerinin arttı̆̆ 1 görülmektedir. Örneğin $5 \mathrm{~N}$ yük altında $500 \mathrm{~m}$ mesafede sürtünme katsayısı matris malzemesi için $0,34, \% 5 \alpha-\mathrm{Si}_{3} \mathrm{~N}_{4}$ içeren kompozitte $0,40, \% 10 \alpha-\mathrm{Si}_{3} \mathrm{~N}_{4}$ içeren kompozitte 0,57 ve \% 15 $\alpha-\mathrm{Si}_{3} \mathrm{~N}_{4}$ içeren kompozitte 0,70 olarak ölçülmüştür. Sonuçlar takviye elemanı oranı artarken sürtünme katsayısının da arttığını göstermektedir [35]. Genel olarak yük artışına bağlı olarak sürtünme katsayısı değerlerinde ciddi bir değişim görülmemektedir. Bütün kompozit numuneler için sürtünme katsayısı değerleri 0,20 ile 0,70 arası değişim göstermektedir (Şekil 5). Mesafe artarken aşınma katsayısı değerlerinde küçükte olsa artma görülürken zaman zaman tersi sonuçlarda ortaya çıkmıştır. Aşındırılan malzemenin toz metal parça olması sinterleşme ve takviye elemanı partiküllerin matris yapı içerisindeki dağılımında yer yer görülen farklılıklardan dolayı farklı sonuçların ortaya çıkması beklenebilir. Genel olarak matris malzemeye göre kompozit malzemelerde sürtünme katsayısı değerinin takviye oranı artışına paralel olarak artıyor olması disk yüzeyindeki bazulmaya bağlı olarak ortaya çıkmaktadır.
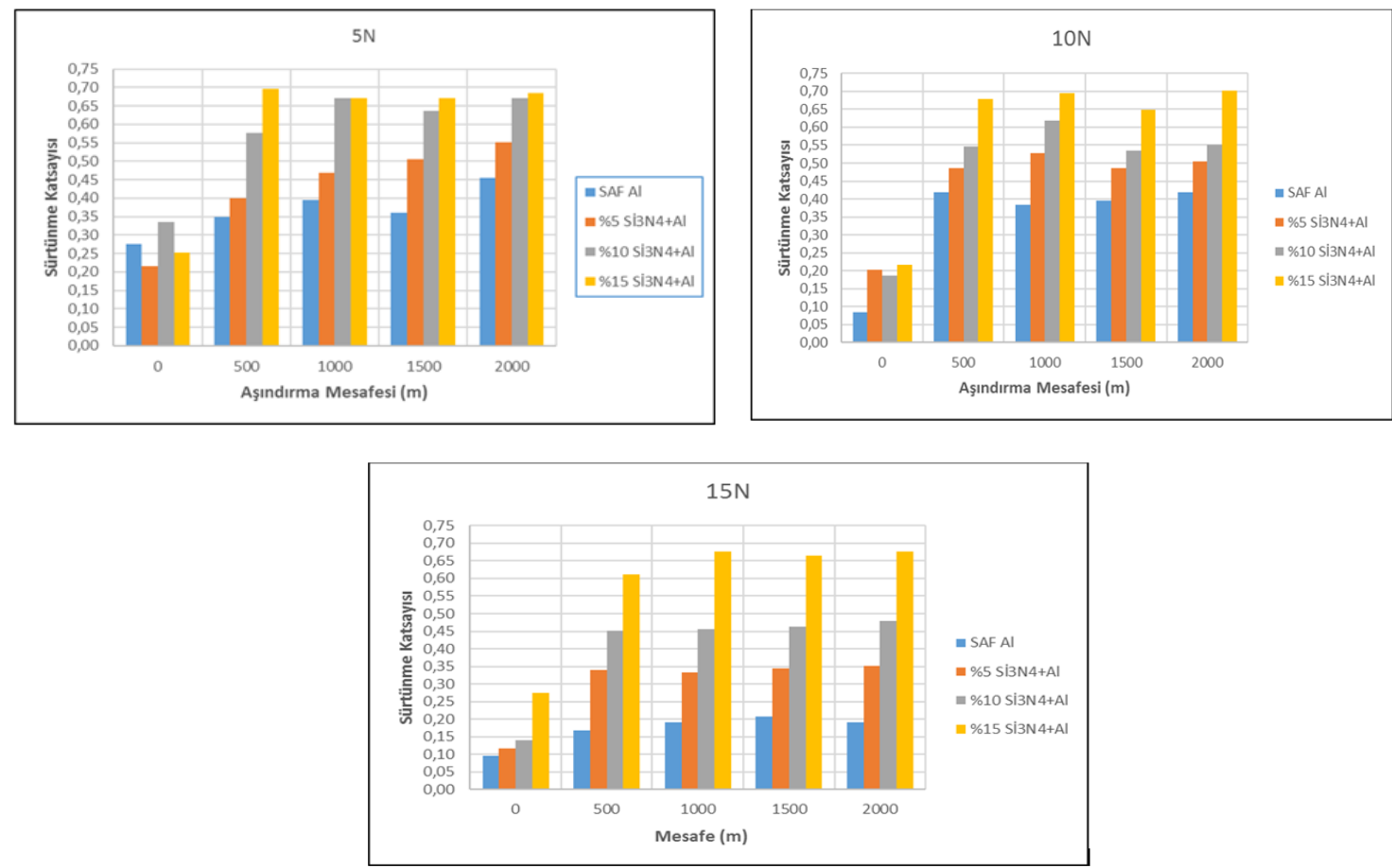

Şekil 5. Değişen yükler altında malzeme kompozisyonuna ve aşındırma mesafesine bağlı sürtünme katsaylsindaki değişim 
Matris malzemesi ve değişen oranlarda $\alpha-\mathrm{Si}_{3} \mathrm{~N}_{4}$ takviye elemanı içeren kompozit toz metal numuneler için değişen yükler altıda ve belirli aşındırma mesafelerindeki sürtünme kuvveti değerleri şekil 6'de verilmektedir. Matris malzeme üzerinden alınan değerler uygulanan yük artışına paralel olarak sürtünme kuvveti değerlerinin arttığını göstermekte. Sürtünme mesafesi artarken bütün yüklerde sürtünme kuvvetlerinin bir miktar arttı̆̆ görülmekte bunun nedeni sürtünmeye bağlı aşındırıcı çelik yüzeyin ve aşınan numunenin yüzey kalitesinin bozulmasından kaynaklandığı söylenebilir. Kompozit numunelerde de benzer şekilde yükteki artışa paralel sürtünme kuvvetlerinin arttığ1 görülürken, bütün kompozit numunelerde aşındırma mesafesi artarken kısmi artış görülmektedir. Numunelerdeki takviye oranı artarken kısmen sürtünme kuvvetlerinde bir düşüş görülse de bu durum bütün yükler ve mesafeler için çok uyumlu görünmemektedir. Bunun sebebi çok dar arlıklardan cihaz veri kaydederken malzemenin kompozit ve toz metal parça olmasından kaynaklı olarak alınan verilerde hem sürtünme katsayısı değerlerinde hem de sürtünme kuvveti değerlerinde ciddi dalgalanmalar olmasındandır.
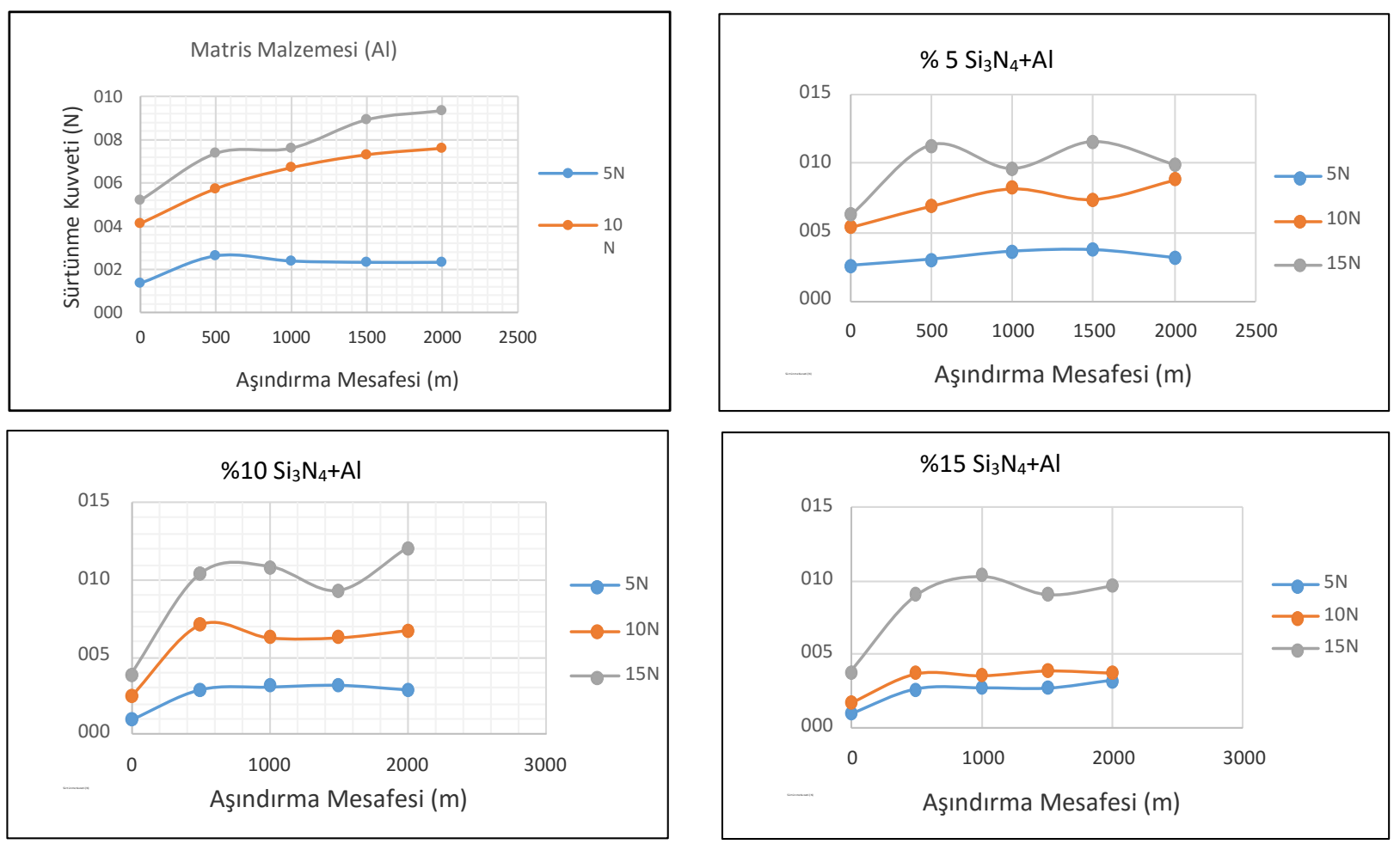

Şekil 6. Matris ve kompozit malzemelerde değişen yükler ve aşındırma mesafelerine bă̆gl sürtünme kuvvetlerindeki değişim.

20 N yük altında yapılan aşındırma testleri sonrası numune yüzeylerinden alınan SEM görüntüleri bütün numunelerde yoğun şekilde deleminasyon türü aşınma mekanizmasının gerçekleştiğini göstermektedir. $\mathrm{Bu}$ tür yüzeyden aşınarak kopan kitlenin takviye elemanının kompozit içerisindeki oranı artarken azalma eğilimine girdiği görülmekte (Şekil 7-9). Elde edilen görüntüler aşınmaya bağlı ortaya çıkan ağırlık kaybı değerleriyle de uyumludur. Aşınan yüzeylerde yer yer kazınma şeklinde abrasiv aşınma mekanizmasının da meydana geldiği bu durum kompozitteki takviye elemanının tesiriyle bozulmuş olan aşındırıcı disk yüzeyinin sebep olduğu şeklinde yorumlanmıştır. $\% 15 \alpha-\mathrm{Si}_{3} \mathrm{~N}_{4}$ içeren kompozitte numune yüzeylerinde kazınarak abrasiv aşınmanın ve deleminasyon türü aşınarak kopan parçacıkların boyutunun küçüldüğü görülmektedir (Şekil 9). 

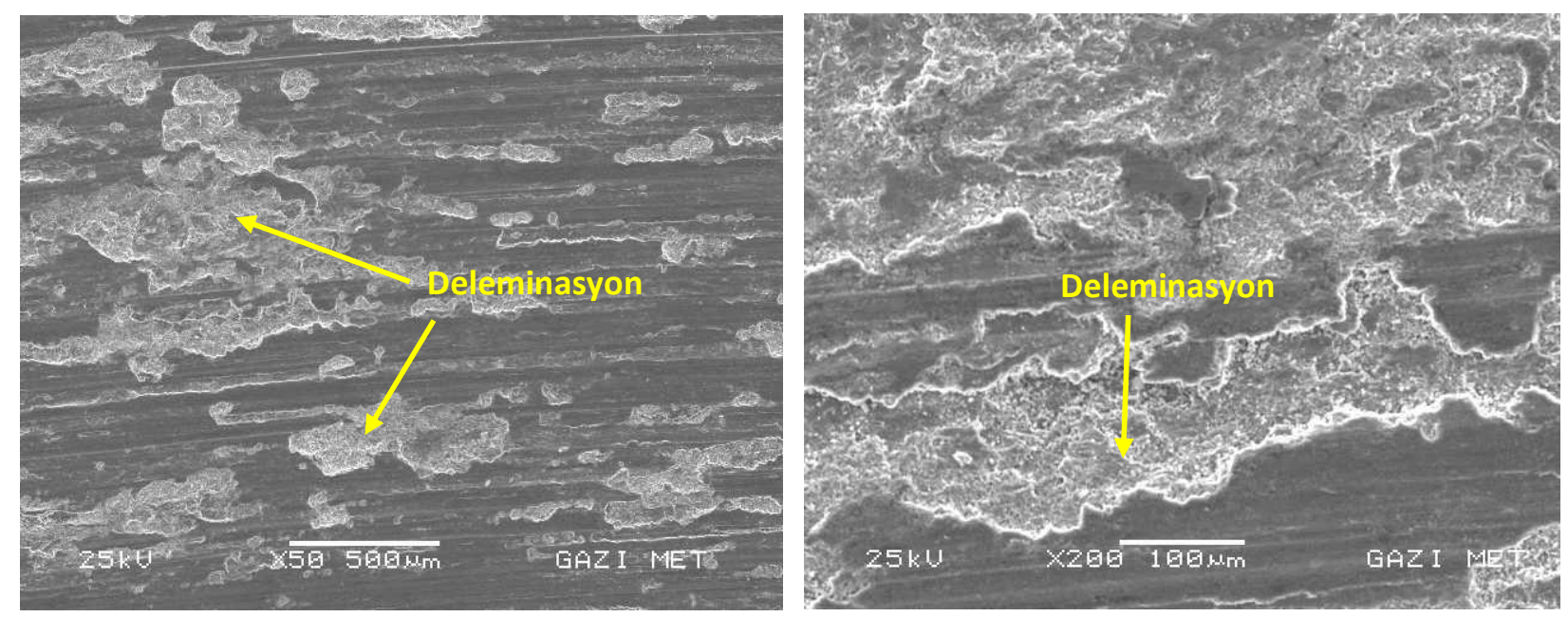

Şekil 7. \% $5 \alpha$-Si $i_{3} N_{4}$ içeren kompozit numunenin 20 Nyük altında aşınma yüzey desenleri
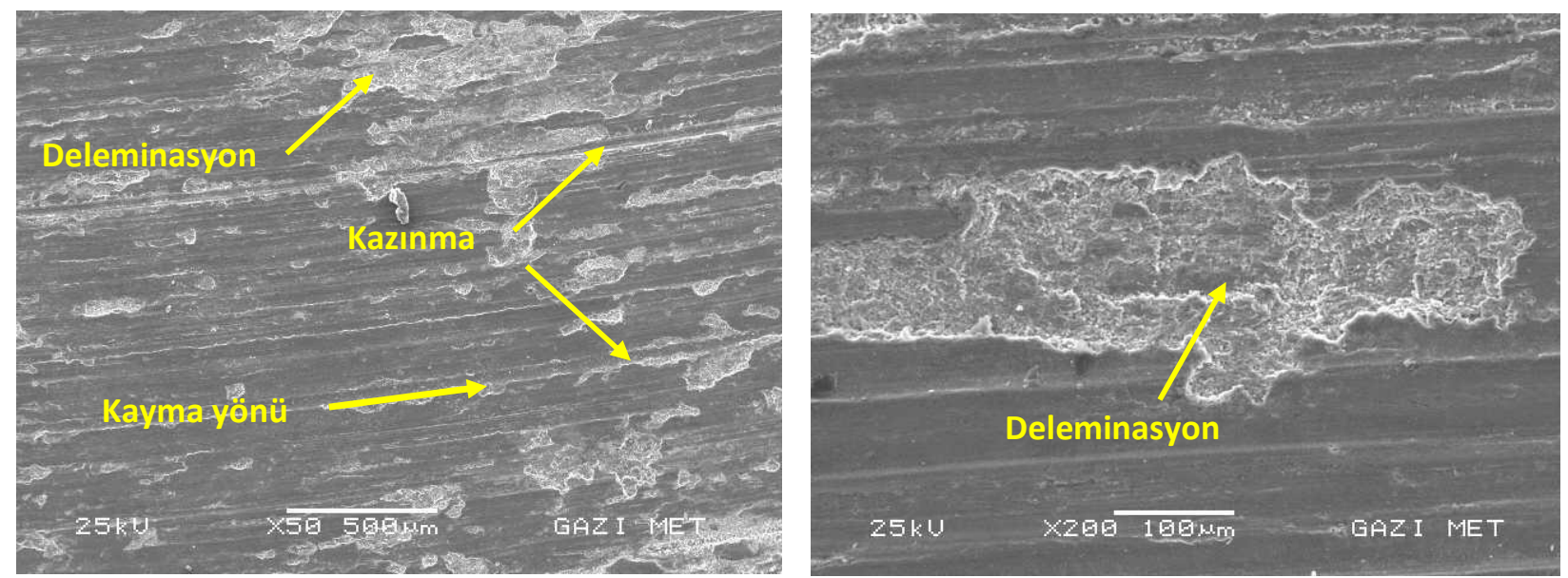

Şekil 8. \% 10 $\alpha$-Si $i_{3} N_{4}$ içeren kompozit numunenin $20 \mathrm{~N}$ yük altında aşınma yüzey desenleri
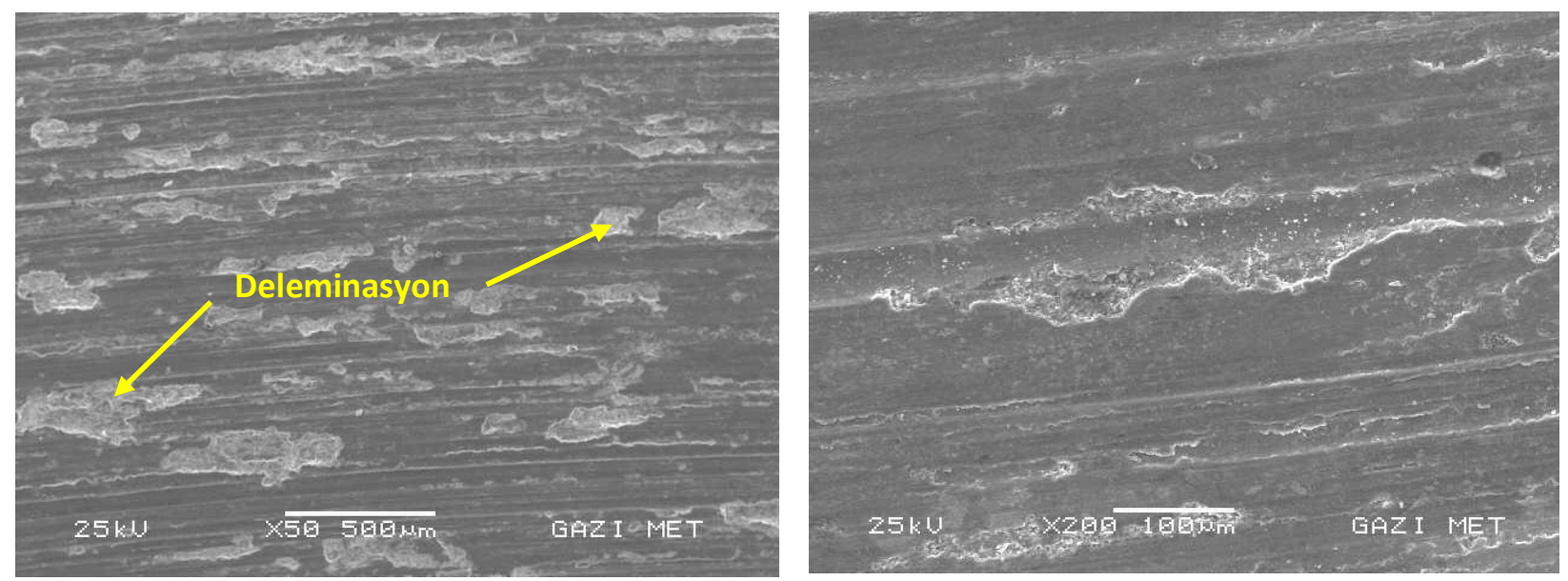

Şekil 9. \% $15 \alpha-\mathrm{Si}_{3} \mathrm{~N}_{4}$ içeren kompozit numunenin $20 \mathrm{~N}$ yük altında aşınma yüzey desenleri

Aşınma sürecinde sürtünme ve basma kuvvetleri tesiri altında deleminasyon (kavkıma) şeklinde kopan veya kopmaya yakın parçaların tabaka halinde yüzeyden ayrıldığı görülmekte. Bu durumda kompozit toz metal parçanın kendi içerisinde sinterleşme derecesi çok büyük öneme sahiptir. Toz metal parçada yeterince sinterleşme olmadığı veya toz partiküllerin ara yüzeylerinde kalan atık ve gözenekler çatlak oluşumuna ve büyümesine sebep olabilir. Aşınmaya maruz kalacak parçalarda bu tip sorunları aşabilmek için yüksek yoğunluk ve sinterleşme ile bağlanmayı mümkün kılan sıcak presleme ile parça üretimi tercih edilebilir. Literatür taramasında karşılaşılan sıvı metal yöntemiyle üretilen benzer kompozisyonda toz metal kompozit 
malzeme üretiminde kısmen daha yüksek yoğunluk ve mukavemet değerleri elde edildiği görülmektedir [36-37] . Şekil 10'da aşınmaya bağlı numune yüzeyinden malzeme kopmuş bir yüzey ve kenar bölgelerden kopmaya yakın parçalar ve buna sebep olan çatlak oluşumu görülmektedir.
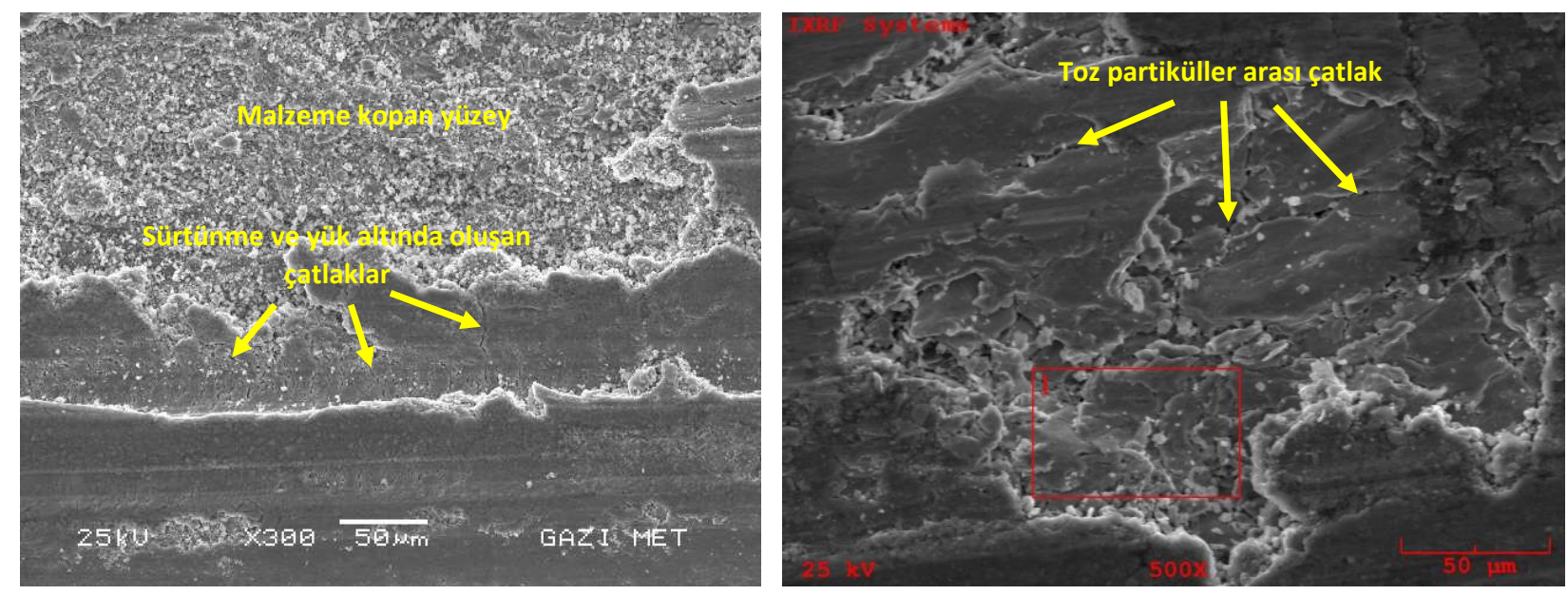

Şekil 10. \% $5 \alpha-\mathrm{Si}_{3} \mathrm{~N}_{4}$ içeren kompozit numunenin $20 \mathrm{~N}$ yük altında aşınan yüzeyinde deleminasyon türü aşınma

Yüzeyden kopan kompozit parçanın oluşturduğu boşluktan alınan SEM görüntüleri kompozit yapıdaki toz partiküllerin birbirlerine sinterlenerek bağlanmalarının kritik öneme sahip olduğunu göstermektedir. Kopan parçanın gerisinde kalan ve aşındırıcı diskle teması kesilen bölgeden alınan SEM-EDX analiz sonuçları kompozit malzemenin içerdiği takviye elemanlarının tesiri altında aşındırıcı diskin çizilmesi sonucu açığa çıkan atıkların kompozit yüzeyini ciddi olarak kirlettiği görülmektedir. Bu bölgeden alınan analiz sonucu kompozit malzeme kompozisyonunda olmayan demiri \% 81,14 mertebesinde göstermektedir (Şekil 10).

\section{Genel sonuçlar (General results )}

1. Toz metalurjisi metodu ile değişen molar oranlarında $\alpha-\mathrm{Si}_{3} \mathrm{~N}_{4}$ içeren alüminyum matrisli toz metal kompozit malzemeler başarıyla üretilmiştir.

2. Matris malzemeye göre kompozit malzemelerde $\% 65^{\prime}$ kadar sertlik artışı sağlanmıştır.

3. Aynı şartlarda üretilen matris malzemeye göre kompozit malzemelerim tümünde aşınma davranışında iyileşmeler görülürken, en yüksek aşınma dayanc1 \% $15 \alpha-\mathrm{Si}_{3} \mathrm{~N}_{4}$ içeren numunede ortaya çıkmıştır.

4. Aşınan numune yüzeylerinden alınan SEM-EDX görüntü ve sonuçları numunelerde deleminasyon tipi aşınma mekanizmasının yoğun olarak ortaya çıktığını göstermektedir.

5. Kompozit numunelerin aşındırılmasında aşındırıcı disk yüzeyi kompozitteki takviye elemanı tarafından çizilerek abrasiv aşınma meydana geldiği bunun sonucu olarak aşınan kompozit numune yüzeylerini kısmen abrasiv aşınma gerçekleştiği görülmekte.

\section{KAYNAKLAR (REFERENCES)}

[1] Rosso M. 2006, Ceramic and metal matrix composites: Routes and properties. Journal of Materials Processing Technology, 175 (364-375), (2006).

[2] Sahu P.S., Banchhor R. Effect of different reinforcement on mechanical properties of aluminium metal matrix composites, Res. J. Engineering Sci., 6 (39-45), (2017).

[3] Mattli M.R., Matli R.R et all. Structural and mechanical properties of amorphous $\mathrm{Si}_{3} \mathrm{~N}_{4}$ nanoparticles reinforced Al matrix composites prepared by microwave sintering. Ceramics, 2 (126-134), (2019).

[4] Mahajan G.V., Aher V.S. Composite material: A review over current development and automotive application, International Journal of Scientific and Research Publications, 2 (1-5), (2012). 
[5] Babalola P.O., Bolu C.A., et all. Development of aluminium matrix composites: A review, Journal of Engineering and Technology Research, 1(1-11), (2014).

[6] Ervina Efzan M.N., Siti Syazwani N., and Abdullah M.M.A.B. Fabrication method of aluminum matrix composite (Amcs): A review, Key Engineering Materials, 700(02-110), (2016).

[7] Ramnath B.V., Elanchezhian C. Alumınıum metal matrıx composites - A review, Advanced Materials Science, 38(55-60), (2014).

[8] Manohar G., Dey A., Pandey K.M. and Maity S.R. Fabrication of metal matrix composites by powder metallurgy: A review, International Conference on Electrical, Electronics, Materials and Applied Science, 020041(1-8), (2019).

[9] Thirumoorthy A, Arjunan T.V., Senthil Kumar K.L. Latest research development in aluminum matrix with particulate reinforcement composites - A review, Materials Today: Proceedings 5(1657-1665), (2018).

[10] Attar S., Nagaral M., et all. A review on particulate reinforced aluminum metal matrix composites, Journal of Emerging Technologies and Innovative Research, 2(225-229), (2015).

[11] Bedir F. Characteristic properties of $\mathrm{Al}-\mathrm{Cu}-\mathrm{SiCp}$ and $\mathrm{Al}-\mathrm{Cu}-\mathrm{B}_{4} \mathrm{Cp}$ composites produced by hot pressing method under nitrogen atmosphere, Materials and Design, 28(1238-1244), (2007).

[12] Kırmızı G., Arık H., Çinici H. Experimental study on mechanical and ballistic behaviours of silicon carbide reinforced functionally graded aluminum foam composites. Composites Part B, 164(345-357), (2019).

[13] O’Donnell G., Looney L. Production of aluminium matrix composite components using conventional PM technology, Materials Science and Engineering A. 303(292-301), (2001).

[14] Kaczmar J.W., Pietrzak K., Wøosinski W. The production and application of metal matrix composite materials. Journal of Materials Processing Technology, 106(58-67), (2000).

[15] Mahdavi S., Akhlaghi FR. Effect of the SiC particle size on the dry sliding wear behavior of sic and sic-gr-reinforced Al6061 composites, J Mater Sci, 46(7883-7894), (2011).

[16] Sureshkumar P., Uvaraja V. Effect of ceramic and metallic reinforcement on mechanical, corrosion, and tribological behavior of aluminum composite by adopting design of experiment through taguchi technique. Journal of Tribology, 140(1-11), (2018).

[17] Kumar M., Gupta R.K., Pandey A. A review on fabrication and characteristics of metal matrix composites fabricated by stir casting. Conference Series: Materials Science and Engineering, 377(19), (2018).

[18] Saravanan R., Vinod K., Tamilarasan T. Investıgation of wear behaviour of al 6061 alloy reinforced with sic, $\mathrm{Al}_{2} \mathrm{O}_{3}$ and e glass fiber. International Journal of Scientific Engineering and Applied Science (IJSEAS), 1(430-434), (2015).

[19] Imran M., Anwar Khan A.R. Characterization of Al-7075 metal matrix composites: A review. J. Materials Research and Technology, 8(3347-3356), (2019).

[20] Ramesh B.T. Characterization of Al based nano composites using powder metallurgy technique. International Journal of Research In Aeronautical and Mechanıcal Engineerıng, 2(131-147), (2014).

[21] William C., Harrigan Jr. Commercial processing of metal matrix composites. Materials Science and Engineering A, 244(75-79), (1998). 
[22] Ambigai R., Prabhu S. Optimization of friction and wear behaviour of $\mathrm{Al}-\mathrm{Si}_{3} \mathrm{~N}_{4}$ nano composite and $\mathrm{Al}-\mathrm{Gr}-\mathrm{Si}_{3} \mathrm{~N}_{4}$ hybrid composite under dry sliding conditions. Trans. Nonferrous Met, 27(986-997), (2017).

[23] Ul Haq M.I., Anand A. Dry sliding friction and wear behaviour of hybrid AA7075/ $\mathrm{Si}_{3} \mathrm{~N}_{4} / \mathrm{Gr}$ self lubricating composites. Mater. Res. Express, 5(1-12), (2018).

[24] Sharma P., Sharma S., and Khanduja D. Production and characterization of AA6082-( $\left.\mathrm{Si}_{3} \mathrm{~N}_{4}+\mathrm{Gr}\right)$ stir cast hybrid composites. Partıculate Science and Technology, 35(158-165), (2017).

[25] Monikandan V.V., Joseph M.A., Rajendrakumar P.K. Dry sliding wear studies of aluminum matrix hybrid composites. Resource-Efficient Technologies, 2(12-24), (2016).

[26] Ambigai R., Prabhu S. Fuzzy logic algorithm based optimization of the tribological behavior of Al$\mathrm{Gr}_{-} \mathrm{Si}_{3} \mathrm{~N}_{4}$ hybrid composite. Measurement, 146(736-748), (2019).

[27] Tyagi A., Sharma D. Characterization of AA6082/ $\mathrm{Si}_{3} \mathrm{~N}_{4}$ composites, 1st International conference on new frontiers in engineering. Science \& Technology, New Delhi, India, January 8-12, (2018).

[28] Sharma P., Sharma S., Khanduja D. Production and some properties of $\mathrm{Si}_{3} \mathrm{~N}_{4}$ reinforced aluminium alloy composites. Journal of Asian Ceramic Societies, 3(352-359), (2015).

[29] Arık H., Semerci P., Kırmızı G. Sicak presleme ile alüminyum matrisli ve $\mathrm{Al}_{2} \mathrm{O}_{3}$ takviyeli toz metal kompozit malzeme üretimi ve aşınma davranışının araştırılması. GU J Sci, Part C, 5(87-97), (2017).

[30] Arik H., Orhun D.Z., Investigation of dry sliding wear behavior of powder metal $(\mathrm{p} / \mathrm{m})$ materials produced from mixture of Fe-Cu-C powders. GU J Sci, Part A, 5 (37-48), (2018).

[31] Arik H. Effect of mechanical alloying process on mechanical properties of $\alpha-\mathrm{Si}_{3} \mathrm{~N}_{4}$ reinforced aluminum-based composite materials. Materials \& Design, 29(1865-1861), (2008).

[32] Ramesh B. T., Arun Kumar M. B., Swamy R.P. Dry sliding wear test conducted on pin-on-disk testing setup for al6061-sic metal matrix composites fabricated by powder metallurgy. International Journal of Innovative Science, Engineering \& Technology, 2(264-270), (2015).

[33] Lawrence O.O., Oluwaseyi O. T., and Samson O. A. The dry sliding wear behaviour of aluminum composites: A review. The West Indian Journal of Engineering, 40(17-23), (2017).

[34] Veeresh Kumar G.B., Rao C.S.P., Selvaraj N. Studies on mechanical and dry sliding wear of Al6061Sic composites. Composites: Part B, 43(1185-1191), (2012).

[35] Rao R.N., Das S. Effect of matrix alloy and influence of sic particle on the sliding wear characteristics of aluminium alloy composites. Materials and Design, 31(1200-1207), (2010).

[36] Ul Haq M.I., Anand A. Dry sliding friction and wear behavior of AA7075- $\mathrm{Si}_{3} \mathrm{~N}_{4}$ composite. Silicon, 10(1819-1829), (2018).

[37] Radhika N., Raghu R. Parametric study of dry sliding wear behaviour of functionally graded Al $\mathrm{LM} 25 / \mathrm{Si}_{3} \mathrm{~N}_{4}$ composite by response surface methodology. Advanced Composites Letter, 24(130-136), (2015). 